\title{
Análisis crítico de las intervenciones de acogimiento residencial en Chile
}

\author{
Bárbara Olivares-Espinoza, $\mathbf{M g} .^{\text {a }}$ \\ Universidad Diego Portales, Chile \\ Camilo Morales-Retamal, Mg. ${ }^{\text {b }}$ \\ Universidad de Chile, Chile
}

barbara.olivares@udp.cl

\section{Resumen (analítico)}

Se busca comprender cómo se organizan las prácticas de intervención con niños y sus familias en residencias. Se realizaron entrevistas en profundidad a ejecutores, diseñadores y especialistas, y se aplicó análisis de discurso. Los resultados dan cuenta de intervenciones heterogéneas e indican que el trabajo directo con los niños se organiza en un continuo, con prácticas subjetivantes habilitadoras de agencia, identidad y sostén psíquico, así como prácticas desubjetivantes que dan cuenta de procesos de objetualización y desarraigo. La intervención familiar varía según el enfoque de cada institución. Se concluye que los equipos pueden mejorar la calidad de su trabajo si se generan otras condiciones institucionales y se reconoce la capacidad de agencia de los niños y sus familias, siendo el cuidado una tarea que implica también al Estado y las comunidades.

\section{Palabras clave}

adolescencia; bienestar de la infancia; Chile; cuidado del niño.

\section{Thesauro}

Tesauro de Ciencias Sociales de la Unesco.

\section{Para citar este artículo}

Olivares-Espinoza, B., \& Morales-Retamal, C. (2022). Análisis crítico de las intervenciones de acogimiento residencial en Chile. Revista Latinoamericana de Ciencias Sociales, Niñez y Juventud, 20(2), 1-27. https://dx.doi.org/10.11600/rlcsnj.20.2.5070

\section{Historial}

Recibido: 03.09.2021

Aceptado: 11.12.2021

Publicado: 18.02.2022

\section{Información artículo}

El artículo presenta los resultados de una investigación más amplia, iniciada en julio de 2020 y finalizada en octubre de 2021, desarrollada en el marco del Doctorado en Ciencias Sociales de la Universidad de Chile, que cursa la autora principal gracias al financiamiento otorgado por la Agencia Nacional de Investigación y Desarrollo, a través del Programa Formación de Capital Humano Avanzado, Beca Doctorado Nacional, No. 21170885. Área: Ciencias Sociales. Subárea: Interdisciplinaria. 


\section{Critical analysis of residential care interventions in Chile}

\section{Abstract (analytical)}

The objective of this research is to understand how intervention practices with children and their families are organized in residential care homes. In-depth interviews were conducted with implementing partners, designers and specialists and discourse analysis was applied. The results evidence heterogeneous interventions and indicate that direct work with children is organized in a continuum. Subjectivizing practices, enable agency, identity and psychic support. Desubjectivizing practices contribute to processes of objectification and uprooting. Family interventions vary depending on the approach of each institution. It is concluded that teams can improve the quality of their work if other institutional conditions are generated and the agency capacity of children and their families is recognized, with care being a task that also involves the State and communities.

Keywords

Adolescence; child care; Chile; child welfare.

\section{Uma análise crítica das intervenções de acolhimento residencial no Chile}

\section{Resumo (analítico)}

O objetivo é entender como são organizadas as práticas de intervenção com crianças e suas famílias em lares residenciais. Foram realizadas pesquisas detalhadas e em profundidade com executores, designers e especialistas, e aplicou-se uma análise do discurso. Os resultados mostram intervenções heterogêneas e indicam que o trabalho direto com crianças é organizado de forma contínua, com práticas subjetivizadoras, que possibilitam a agência, a identidade e o apoio psíquico, e práticas des-subjetivadoras, que representam processos de objetivação e desenraizamento. A intervenção familiar varia de acordo com a abordagem de cada instituição. Conclui-se que as equipes podem melhorar a qualidade de seu trabalho caso se verifiquem outras condições institucionais e se reconheça a capacidade de agência das crianças e suas famílias, sendo o cuidado uma tarefa que também envolve o Estado e as comunidades.

\section{Palavras-chave}

Adolescência, bem-estar infantil, Chile, cuidado infantil.

\section{Información autores}

[1] Psicóloga. Candidata a Doctora en Ciencias Sociales, Universidad de Chile. iD 0000-0001-8239-8910. Índice H5: 0. Correo electrónico: barbara.olivares@udp.cl

[2] Psicólogo. Magíster en Clínica Psicoanalítica con Niños y Jóvenes, Universidad Alberto Hurtado. Índice H5: 0. Correo electrónico: camilomorales@uchile.cl iD 0000-0002-7152-1415. 


\section{Introducción}

R eferirse a la experiencia de los niños, niñas y adolescentes (en adelante NNA) name) es retratar los efectos sistemáticos de la pobreza en sus vidas. Los NNA pobres constituyen el foco de la política pública de protección especial a la infancia, viven en las residencias de protección y han formado parte del sector más excluido de la población (Baratta, 2008; García-Méndez, 1994). Históricamente, los programas de atención de la niñez en Chile se han enfocado en intervenir a las infancias que no logran entrar al proyecto de modernidad, ya sea por pobreza o por ilegitimidad (Delgado, 2001; Farías, 2003; Pinochet, 2017; Rojas, 2010). Datos actuales señalan que la mayoría de los NNA que se encuentran en acogimiento residencial en Chile provienen de familias carentes de recursos, siendo el tipo de intervención residencial el que concentra un mayor porcentaje de familias en situación de pobreza (77\%) (Contreras et al., 2015).

Los NNA pobres encarnan posiciones que alteran el ideal esperado para la infancia (Bustelo, 2007; Cárdenas, 2013) que, en concreto, los ubica como hijos de una familia (habitualmente heteronormada) o como alumnos de una institución escolar. Mientras se mantengan en los cauces del proyecto de infancia moderna, aún imperante en nuestra sociedad (Isacovich \& Grinberg, 2020), el Estado toma distancia y deposita en estas instituciones (familia y escuela) la responsabilidad de su socialización (Minnicelli, 2004). Sin embargo, si alguna de estas instituciones falla en su función organizadora de lo social, se activan mecanismos de vigilancia y corrección que derivan en el ingreso de los NNA a los sistemas de protección especializada (Grinberg, 2016; Villalta, 2013).

De este modo, las residencias de protección forman parte del conjunto de estrategias de autodefensa que la sociedad creó - y ha preservado- cuando las capas pobres representaban un peligro para el contrato social; ello incluía la separación transitoria del niño de la familia de origen, hasta el extremo de eliminar los focos de peligrosidad (Donzelot, 1998; Morales-Retamal, 2014; Pilotti, 2001; Rojas, 2010). 
Actualmente, las residencias siguen trabajando con los NNA pobres y esa dimensión atraviesa toda la presente política de infancia. ¿Qué ocurre con los equipos que intervienen a los NNA pobres? Precisamente ese es el foco de este trabajo, el cual se propone comprender qué prácticas y qué arreglos despliegan los equipos profesionales en el trabajo residencial.

La institucionalización de los NNA en Chile corresponde a una medida de protección que opera como último recurso, ya que, en principio, debiese ser excepcional y transitoria (Marchant, 2014; Organización de las Naciones Unidas [ONU], 2009). Sin embargo, actualmente el contexto residencial chileno está lejos de responder a estos principios. A la fecha, hay cerca de 5000 NNA viviendo bajo el cuidado estatal en residencias de protección administradas por el mismo Estado (administración directa, en la cual habitan alrededor de $774 \mathrm{NNA}$ ) o por los denominados organismos colaboradores (en donde habitan cerca de 4585 NNA) que reciben subvención estatal - a partir de la firma de un convenio- por cada NNA atendido/a, concentrando cerca de un $71 \%$ de la oferta residencial (Defensoría de la Niñez de Chile, 2020).

Los problemas que presenta el ámbito residencial en Chile han sido ampliamente documentados (Consejo Nacional de la Infancia, 2017; García-Quiroga \& Hamilton-Giachritsis, 2014; Hogar de Cristo, 2017; Lecannelier, 2006; Marchant, 2007; Milanich, 2001; Rojas, 2010). En los últimos años han quedado al descubierto los castigos y vejaciones sistemáticas contra los NNA, develando la débil labor de cuidado realizada por las instituciones que deben protegerlos (Instituto Nacional de Derechos Humanos [INDH], 2017; ONU, 2018; Rojas, 2020).

Uno de los principales problemas detectados por los distintos organismos interesados en visibilizar la situación al interior de las residencias (Policía de Investigaciones de Chile [PDI], 2018; Servicio Nacional de Menores [Sename], 2018; ONU, 2018; Universidad Diego Portales [UDP], 2017) son las serias falencias para desarrollar el trabajo de reintegración familiar de los NNA. Esta falta agudiza la pérdida de vínculos, profundiza la separación y genera un aumento en los tiempos de permanencia (Consejo Nacional de la Infancia, 2017; Morales-Retamal, 2019; Muñoz-Guzmán et al., 2015; UDP, 2008; Unicef, 2002).

La evidencia indica que los equipos responsabilizan a los padres y madres de la vulneración del niño o niña, lo que instala una cierta desconfianza al momento de trabajar y acompañar a las familias. Lo anterior acentúa el estigma y la devaluación, volviendo cada vez más difícil el proceso de revinculación, que finalmente decanta como abandono (Morales-Retamal et al., 2015; Muñoz-Guzmán et al., 2015; Silva \& Domínguez, 2017). 
Por otro lado, se declara que existe una ausencia de trabajo de intervención psicosocial con las familias y adultos relacionados y que, aunque se afirme contar con planes de intervención que explicitan objetivos de revinculación familiar, la periodicidad de dichas intervenciones no asegura un trabajo concreto y estable con esas familias (Consejo Nacional de la Infancia, 2017; Mide UC, 2013; Sename, 2018). De manera más específica, también se ha constatado que la mayoría de las residencias cuentan con horarios restringidos para la realización de llamadas y visitas de las familias, siendo generalmente limitados a unas horas y solo algunos días de la semana (Defensoría de la Niñez de Chile, 2020). Junto con ello, preocupa que un $57 \%$ de las residencias no se encuentren localizadas en la comuna de origen familiar y que un $6 \%$ ni siquiera se emplaza en la misma región, potenciando el desarraigo y aislamiento de los NNA (INDH, 2017).

La intervención sobre las familias en contextos residenciales ha ido cobrando relevancia en los últimos años a partir de las recomendaciones internacionales que señalan la importancia de los procesos de desinternación y revinculación familiar (Cantwell et al., 2012; Comisión Interamericana de Derechos Humanos, 2013; ONU, 2009). En el contexto chileno, hace apenas diez años el Estado consideró que era importante incluir a las familias en el proceso de intervención, estableciendo como meta la revinculación de los niños y niñas institucionalizados con sus contextos de origen, desincentivando así la larga estadía y la cronificación de la institucionalización (Consejo Nacional de la Infancia, 2017; Contreras et al., 2014; Gobierno de Chile, 2018). Con todo, las cifras dan cuenta de un trabajo escaso y poco sistemático, pues las intervenciones familiares que se producen en los programas especializados de Sename solo alcanzan un $22 \%$ del total de intervenciones realizadas por los equipos profesionales (Contreras et al., 2015).

El trabajo con familias, identificado en el marco de las políticas protección en Chile, asume los vínculos entre madre-hijo como foco preponderante, comprendidos, exclusivamente, en clave psicológica (Calquín et al., 2020; Castillo, 2015). Los equipos profesionales desarrollan un plan de trabajo que implica operar sobre los vínculos de cuidado, los que terminan siendo tecnificados, de manera rutinaria, a través del lenguaje instrumental de las habilidades (en Chile, las políticas públicas las ha llamado competencias parentales). Estas últimas, puestas en el individuo (fundamentalmente la madre), invisibilizan el contexto como un factor determinante en la crianza y el cuidado (Villalta, 2021). De este modo, las vulneraciones de derecho de NNA encuentran su causa en las responsabilidades individuales de los adultos cuidadores y no en la distribución desigual de bienes 
y privilegios, produciendo una clara normalización de la desigualdad social (Castillo et al., 2021; Gillies, 2014).

Centrar el foco únicamente en la dimensión familiar como causa del ingreso de los NNA a los sistemas de protección ha implicado reducir las intervenciones a un espectro muy limitado de acciones; esto pone como centro el supuesto de que la pobreza y la desventaja son fallas personales asociadas con una maternidad pobre, que ha fracasado en su rol cuidador y que no ha estimulado como corresponde a sus hijos/as (Edwards et al., 2015).

Por otro lado, no se visibiliza suficientemente la importancia de construir contextos de cuidado que permitan a los NNA tener experiencias donde puedan reparar las vulneraciones vividas y elaborar los efectos de la separación afectiva a través del reconocimiento de su historia y de su subjetividad (Marchant, 2014; Silva \& Domínguez, 2017).

Ocasionalmente, las residencias actúan como instituciones totales que se caracterizan por sus mecanismos de coacción, regulación y homogenización de las experiencias de los sujetos (Foucault, 1978; Goffman, 2007). Se orientan principalmente a la adaptación de los NNA al contexto antes que propiciar su bienestar y el reconocimiento de sus particularidades, intereses y deseos. Siguiendo a Wieviorka (2003), se trataría de contextos que operan negando la subjetividad, es decir, produciendo la imposibilidad para que los sujetos puedan actuar de forma autónoma, creativa y constituir su propia existencia junto con otros.

A su vez, la realidad de las residencias de protección es heterogénea y se configura a partir de diversas prácticas que operan sobre las experiencias de los NNA y sus familias (Silva \& Domínguez, 2017). En tal sentido, también se van desarrollando prácticas y discursos que reconocen a los NNA y sus familias como sujetos con dignidad y derechos (Eliacheff, 2002). Reconocer estas prácticas es clave para el mejoramiento de las intervenciones en los contextos de cuidados alternativos.

A partir de lo señalado, el objetivo de este trabajo es caracterizar los modos en que se interviene a los NNA que se encuentran bajo cuidado estatal, identificando, por un lado, aquellas prácticas que reconocen -o no- una subjetividad que contiene deseos, expectativas e historia y, por otro, prácticas que habilitan $-\mathrm{O}$ no- un soporte de cuidado que restituya posibilidades para la revinculación familiar y que posibiliten un retorno a los contextos de origen y a la trama social de la que fueron distanciados. 


\section{Método}

Se utilizó una metodología cualitativa (Stein \& Mankowski, 2004), con un diseño descriptivo para indagar el fenómeno en estudio, mediante la identificación detallada de sus dimensiones centrales (Hernández et al., 2010). En particular, se optó por el estudio de caso, pues la pregunta gira en torno al cómo y al por qué; además, el foco está puesto en un fenómeno contemporáneo dentro de un contexto de la vida real, donde se utilizan múltiples fuentes de evidencia que se integran en el mismo análisis (Forni, 2010).

\section{Participantes}

Participaron 20 operadores del sistema de protección: dos encargados del diseño, 12 encargados de implementar y seis especialistas. Se optó por un muestreo estratégico o por conveniencia, donde la selección de unidades muestrales responde a criterios subjetivos pertinentes a los objetivos de la investigación. Se trata de una selección que contiene distintas unidades que representan la heterogeneidad discursiva que resulte teóricamente relevante para la comprensión del fenómeno (Batthyàny et al., 2013). La caracterización de las personas entrevistadas se presenta en la tabla 1.

\section{Técnicas de producción y análisis de la información}

Para la producción de la información se utilizó la entrevista en profundidad, la cual permite acceder a las creencias, deseos, formas de interpretación y significados que los sujetos portan sobre el fenómeno residencial (Gainza, 2006).

Los tópicos abordados para las/os diseñadores se relacionan con: los principales avances de la política residencial junto con los nudos críticos y aspectos por mejorar, la relación que establece la política pública con el ámbito académico, las experiencias destacadas en la implementación del modelo, alternativas existentes para el cuidado residencial, etc. Para el caso de los/as ejecutores/as, se preguntó sobre su experiencia como ejecutor/a, las fortalezas y debilidades percibidas en la implementación, los aspectos necesarios de mejorar o cambiar, las prácticas exitosas (o buenas prácticas), el uso de conocimiento experto, entre otros. Por último, a los/as especialistas o expertos/as se les preguntó por: trayectoria como investigador o especialista en la materia, consensos en el campo, aspectos controversiales o principales tensiones, desafíos para la investigación en este campo, relación entre Estado y ámbito académico, entre otros. 


\section{Tabla 1}

\section{Participantes}

\begin{tabular}{lccc}
\hline $\begin{array}{c}\text { Tipo de } \\
\text { entrevistado/a }\end{array}$ & Pseudónimo & Edad & Profesión u ocupación \\
\hline Diseñadores/as & Carlos & 38 años & psicólogo \\
& Bélgica & 59 años & profesora \\
Carola & 39 años & psicóloga \\
& Vilma & 32 años & psicóloga \\
& Karina & 38 años & psicóloga \\
& Viviana & 23 años & licenciada en educación \\
& Lorena & 25 años & ingeniera civil industrial \\
Ejecutores/as & Milena & 41 años & psicóloga \\
& Fabian & 33 años & psicólogo \\
& Claudia & 50 años & profesora \\
& Karol & 57 años & técnico en educación parvularia \\
& Carmen & 29 años & técnico en educación parvularia \\
& Nora & 32 años & trabajadora social \\
& Alberto & 39 años & trabajadora social \\
& Bastián & 35 años & abogado \\
& Susana & 28 años & psicóloga \\
& Soledad & 35 años & periodista \\
& Fernando & 51 años & abogado \\
& Osvaldo & 50 años & psicólogo \\
& Antonia & 40 años & abogada \\
\hline & & &
\end{tabular}

Todo el material producido a partir de las entrevistas fue procesado con análisis de discurso, debido a que el foco está puesto en la comprensión de las prácticas residenciales, conformadas por dichos y hechos colectivizados donde se articula discurso y poder (Bührmann \& Schneider, 2019).

\section{Procedimiento}

Se realizaron 20 entrevistas en total, las cuales permitieron alcanzar una saturación teórica aceptable de la información producida. Las entrevistas se realizaron entre octubre de 2020 y octubre de 2021. Todas las personas entrevistadas aceptaron voluntariamente ser parte de la investigación y firmaron el correspondiente consentimiento informado, visado por el Comité de Ética de la Investigación de la Facultad de Ciencias Sociales de la Universidad de Chile.

Cada persona entrevistada fue contactada inicialmente, a través de correo electrónico (formato tipo) o por un sistema de mensajería instantánea como WhatsApp, momento 
en el que la persona investigadora daba a conocer en qué consistía la investigación y cuál era el requerimiento específico de participación solicitado.

Todas las entrevistas fueron realizadas por la autora principal de este artículo, a través de la plataforma Zoom, debido a las restricciones de movilidad activadas producto de la pandemia del COVID-19. Cada entrevista fue grabada y transcrita para su análisis posterior.

\section{Resultados}

Los resultados de la investigación fueron organizados en dos grandes ejes que buscan caracterizar la experiencia de intervención residencial que se observa como heterogénea. El primer eje refiere al trabajo directo con los NNA; allí convergen prácticas subjetivantes y desubjetivantes que cohabitan incluso en una misma residencia. Estas prácticas podrían ser entendidas como los polos de un continuo, donde se van ubicando los modos de intervenir que ocurren dentro del ámbito residencial. El segundo eje refiere al trabajo con familias, donde el material fue organizado en dos subcategorías: las intervenciones de soporte a las familias y las intervenciones que visualizan a la familia como problema.

\section{Trabajo con niños, niñas y adolescentes}

\section{Prácticas subjetivantes}

Se relaciona con una comprensión de los NNA como sujetos por parte de quienes desarrollan intervenciones al interior de las residencias, y que habilita el despliegue de prácticas respetuosas de la subjetividad de los NNA; estas consideran su historia y su contexto de origen para, desde ahí, comprender sus necesidades y demandas. También se incluyen prácticas dirigidas a las familias, donde se las reconoce como actores fundamentales del proceso. Una de las ejecutoras entrevistadas ejemplifica cómo un asunto muy técnico - como escribir un informe para tribunales - puede ser una oportunidad para incluir la voz de los NNA y ofrecer una relación que los fortalezca en su agencia:

Yo recuerdo con los niños más grandes, yo hacía los informes junto con ellos. O sea, habían [sic] cosas que probablemente no se las iba a mostrar, pero a veces se los leía, algunas partes. Les preguntaba qué querían que yo dijera en la audiencia. Y ahí me acuerdo muy bien una vez que una niña me dijo que ella se quería ir en adopción y que lo había hablado con su abuelita. Y claro po' [pues], yo tenía la cita textual [gesto de comillas] en el informe y se lo dije a la jueza (...). Pero para mí es importante darle ese lugar. Pero no, no hay espacio para esa escucha. (Vilma, psicóloga, ejecutora) 
Otra ejecutora destaca la sensibilidad para escuchar los intereses de los NNA de parte de todos los miembros del equipo (incluida la persona encargada de cocinar); ello permite que asuntos como los gustos y preferencias (que conforman una identidad y se inscriben como historia en la vida de estos NNA) se hagan parte de intervenciones que ocurren en la vida cotidiana, lo que constituye un espacio privilegiado para resignificar sus experiencias de vulneración a partir de la construcción de un vínculo afectivo y de la experiencia de sentirse bien cuidado (García-Quiroga \& Urbina, 2021; Sánchez-Reyes et al., 2019):

Un niño en [nombre residencia] peruano (...), que en un momento llega y le dice a la cocinera: «Tía María, su comida es muy deliciosa, pero ¿me podría hacer ají de gallina?». Y la tía María: «Moya [expresión que denota ignorancia sobre algo], ¿cómo era el ají de gallina?» Pero generamos la condición para que todos los niños probaran el ají de gallina. (Macarena, psicóloga, ejecutora)

Cada intervención constituye un cúmulo de aprendizaje que, muchas veces, permite a los equipos innovar y producir nuevos modos de conceptualizar y de intervenir. Un ejecutor, que se encuentra implementando un nuevo modelo piloto de residencia, comenta que se han esforzado por trabajar con adolescentes, respetando los tiempos y necesidades específicas, dependiendo de la singularidad de cada sujeto, sin asumir un criterio estándar que opere de la misma manera en todos los casos. El interventor reivindica el lugar de sujeto del y la adolescente, así como la capacidad de los equipos para producir respuestas pertinentes y ajustadas a la realidad de cada uno/a:

Nosotros no hablamos de un plan de vida independiente, porque entendemos que nadie es independiente en ningún momento de la vida; que todos requerimos redes, que a los 18 años no se te activa un chip en la cabeza que te dice que te permite ser independiente en el fondo y valértelas por ti mismo. Nosotros planteamos un modelo de vida interdependiente, donde el joven o esta joven siempre va a requerir alguna red de apoyo - ya sea familiar, estatal-, se va a movilizar en un contexto. No va a estar solo en el fondo. Y en eso también aporta a la dupla de familia. (Felipe, psicólogo, ejecutor)

La caridad y el asistencialismo son elementos vigentes en el acogimiento residencial y se observan en prácticas como el voluntariado, donde los NNA quedan situados, en lugar de ser receptores pasivos del cuidado y la asistencia. En la actualidad, se busca producir otros marcos de trabajo desde donde se promueva una perspectiva habilitadora y respetuosa que considere a los NNA como sujetos. 
Hay temas que son como ideas-fuerza; por ejemplo, siempre llamar por su nombre a los niños, no pensar que son pobrecitos o huérfanos y privilegiar la compañía por sobre llevarle cosas materiales, no darles dinero a los niños que tienen historias de vida muy difíciles, complejas; han sido vulnerados gravemente en sus derechos, pero siguen siendo niños. Establecer la relación desde ahí, no desde la lástima, desde la pena, sino de una relación horizontal desde ese punto de vista. (Felipe, psicólogo, ejecutor)

Un tema relevante que es permanentemente observado cuando se monitorea el trabajo residencial es la participación de los NNA (García-Quiroga \& Salvo, 2020). Son escasas las experiencias de participación, pero cuando se producen, vehiculizan una serie de recursos que fortalecen el cuidado y la protección. Una de las entrevistadas destaca lo que ocurrió en su residencia (es la directora), en el contexto del denominado «estallido social» y en relación al gran interés por participar en asambleas y cabildos, en tanto espacios de deliberación y articulación colectiva:

Sí, mira, hemos hecho asambleas internas, como también conversatorios con ellas. Al principio fue muy desde ahí, desde escucharlas y ya después decidimos sacarlas fuera y que empezaran a participar en espacios más colectivos. Entonces empezaron a ir a debates, a conversatorios. De hecho, fueron a uno a la [Universidad de] Chile; fueron a otro a Recoleta (...). Eh, ellas participaron de las asambleas, eh... Y en algún momento también fueron monitoras de asamblea, las más grandes, las que quisieron (...). Hicimos asambleas de los seis años hacia arriba, así que algunas hicieron grupos, eh, a cargo de los más chicos. Después ya, cuando ya estaban un poco cansadas de las asambleas, como todos [risas], empezaron a participar en lo que era teatro, pinta caritas, intervenciones en la calle. Bueno, ellas han participado de las marchas también, de algunas intervenciones. (Karina, psicóloga, ejecutora)

Resulta interesante advertir que las prácticas que acá denominamos como subjetivantes transcurren en espacios diversos, que van desde pequeñas posibilidades que se abren cuando un NNA puede decir qué comida le gusta, hasta hacerse parte de los espacios disponibles en el extramuro, para sumarse a las dinámicas de transformación que irrumpen en el espacio público como las asambleas y los cabildos.

\section{Prácticas desubjetivantes}

Esta categoría agrupa los discursos de los/as entrevistados/as que destacan las prácticas que se producen al interior de las residencias y que ubican a los niños y niñas como objetos, sin deseos ni necesidades, expuestos a la arbitrariedad del mundo adulto que 
decide asuntos sin su opinión ni consulta. En la siguiente cita, una ejecutora destaca cómo prevalece el criterio material por sobre asuntos vinculados, especialmente, al bienestar subjetivo de niños pequeños:

Como el sistema no procura la protección, sino que, sobre todo en el caso de los niños pequeños, se transforman en objetos preciados que son resituados y trasladados de un lugar a otro, creyendo que con ese gesto va a haber un mejor porvenir. (Milena, psicóloga, ejecutora)

Otra expresión vinculada a la anterior, es decir, con la materialidad de la protección, se relaciona con lo que ocurre cuando los adultos que financian la estadía de los niños en las residencias asumen una especie de apropiación de estos, tal y como ocurría con las élites y su relación con los NNA pobres de principios de siglo XIX (Milanich, 2001):

Aparece la hija también de uno de ellos [miembros del directorio de una fundación religiosa que financia una residencia]. Salgo a fumar un cigarro afuera para respirar [la situación le producía ansiedadl y llega y me dice: «Oh, tú eres la psicóloga. ¿Cuándo me puedo llevar a la [nombre de una niña que vivía en la residencia]?» (...). Y le digo a la cara: «Nunca, jamás, olvídalo. Los niños no están para eso. Aquí están para protegerlos. Y esa acción que tú me estás diciendo, ¿cuál es el alcance de su protección? ¿Para qué?» Y hasta ahí llegó la conversación con esa chica, en ese minuto. Una cabra [muchacha] joven, dieciocho años, que también viene con esta deformación de la idea de salvar y llevarlo a la casa a jugar Playstation ¿no? Muy raro. (Macarena, psicóloga, ejecutora)

La circulación por el circuito residencial de los NNA es otro problema que se observa, sin que exista una preocupación por sus vínculos. Muy por el contrario, lo que prevalece es el criterio burocrático que determina la ubicación de niños y niñas en ciertos lugares, en función de la disponibilidad de cupos, obviando lo relevante que resulta preservar el vínculo entre hermanos (no siempre se los ubica a todos en una misma residencia) o con un adulto significativo en particular (cuidador/a).

También pasa que, claro, a veces, los niños salen del sistema y vuelven a entrar; y tampoco es como que los reubican en uno en el que ya hayan estado, sino que es como, ya, en el que tenga plaza [cupo dispuesto por cada licitación]. Al que tenga una plaza lo incorporamos. (Lorena, ejecutora, voluntaria) 
Uno de los aspectos más referidos se relaciona con una ausencia radical de participación que se expresa en distintos niveles y que promueve prácticas adultocéntricas, sostenidas en la caridad, donde los adultos deciden por los niños y niñas, aspectos vinculados a la alimentación o vestimenta.

Los niños, niñas y adolescentes, en general, en las residencias no pueden opinar ni incidir efectivamente en las decisiones que cruzan su vida cotidiana, en todos los ámbitos que tú te puedas imaginar, desde, por ejemplo, cómo se visten. Y eso tiene que ver principalmente, por ejemplo (y ahí hay otro tema muy grande), y es que ellos muchas veces no pueden comprar su propia ropa, porque esta ropa es donada, es entregada por otros. Y desde esta lógica también súper caritativa, del voluntariado y de la beneficencia, son otras instituciones las que vienen a entregar estas cosas a los niños, niñas y adolescentes, dadas, que ellos no pueden escoger; ellos solamente reciben. (Susana, psicóloga, experta)

Hay quienes han manifestado que las residencias funcionan como instituciones totales (Goffman, 2007), donde la intervención se aplica masivamente. Existe una fuerte tendencia a la homogenización de la vida y una ruptura con la vida previa al encierro. La configuración del espacio presenta una clara delimitación entre el adentro y el afuera, existiendo muros, rejas, puertas cerradas, que aíslan la vivencia de sus habitantes de su entorno más directo y de la vida social en su conjunto. Se produce, en estos casos, una discontinuidad con la vida familiar y comunitaria que no es reconocida por el contexto institucional.

La siguiente cita ilustra la experiencia totalizante, donde el efecto desubjetivante afecta los procesos de identidad y pertenencia, los cuales son fundamentales en el desarrollo de los NNA:

Los niños tampoco se sienten en la libertad, por ejemplo, de mencionar su historia, de llevar su historia a esos espacios donde están y tenerla presente en sus habitaciones y en los distintos espacios. Tener fotos de sus familias, tener a la vista cartas, álbumes de fotos, peluches de infancia; ese tipo de cosas, porque en el fondo existe este como discurso implícito - y a veces explícito-, pero muy implícito también, pero muy presente, de que eso ya pasó. Esa es una parte oscura, problemática de tu pasado. Acá hacemos borrón y cuenta nueva; este es un corte. (Susana, psicóloga, experta)

En algunos casos, estas prácticas objetualizantes se transforman en vulneraciones graves a los derechos de los NNA, las cuales se expresan en daños y en una completa revictimización. Ubicar a los niños y niñas en el lugar de objetos (arrebatarles su condición 
de sujetos) produce un daño irreparable, que para algunos autores es conocido como una doble vulneración (Marchant, 2014); pues en lugar de reparar el daño que estuvo en el origen de su ingreso al sistema, se termina produciendo una nueva violencia, ahora de parte de la institución que declaró brindar protección y cuidado (el que la familia no estuvo en condiciones de ofrecer).

En las siguientes citas se destaca la alta medicación al interior de algunas residencias (en donde los NNA reciben fármacos de manera sistemática), la ineficacia de las intervenciones existentes en la propia red y la clara deficiencia del intersector:

Son cosas que hemos podido ver y que a mí nunca me han preguntado, pero sí nos ha pasado con algunos niños - los menores sí-, que los hemos visto en el tiempo y que están altamente medicados. Uno los nota, porque cuando les habla no tienen el sentido de seguir la voz, se les cae la saliva. Y uno va notando ese tipo de cambios. (Lorena, ejecutora, voluntaria)

Tenemos que salud mental la atiende una vez cada dos meses, media hora. Los tratamientos farmacológicos no dan mucho, mucho efecto. Más del noventa por ciento de nuestras chiquillas tiene problemas de salud mental grave. Sin tratamiento; sin procesos psicológicos tampoco. Con trayectorias de derivación a proyectos de Sename, pero fallidas. PRM, ${ }^{1}$ explotación. Eh, los procesos judiciales que avanzan infinitamente lentos. (Alberto, trabajador social, ejecutor)

En síntesis, las y los entrevistados dan cuenta de prácticas sistemáticas que vulneran en lugar de cuidar, que son consistentes con las denuncias que organismos nacionales e internacionales (ONU, 2018; PDI, 2018; Sename, 2018; UDP, 2017) han hecho sobre el funcionamiento al interior de las residencias.

\section{Trabajo con las familias}

Las intervenciones que se orientan a las familias y que son caracterizadas por los/as entrevistados/as se pueden organizar en dos grandes grupos. El primero, donde se encuentran las intervenciones que comprenden a la familia desde una perspectiva que reconoce su complejidad y diversidad (intervenciones de soporte o sostén) y donde se incluye una comprensión de las causas del ingreso a las residencias que va más allá del comportamiento, considerando dimensiones estructurales a la base de las dificultades y limitaciones en el ejercicio de cuidado. Y, por otro lado, está un segundo grupo que ven a la familia

\footnotetext{
${ }^{1}$ Programas de protección especializada en maltrato y abuso sexual infantil del Servicio Nacional de Menores.
} 
como la causa y el problema que está a la base de la institucionalización de los NNA. Los esfuerzos de los equipos residenciales se orientan a corregirla en su función de cuidado, centrando las acciones en la evaluación y el mejoramiento de sus habilidades parentales.

\section{Intervenciones de soporte o sostén a las familias}

Se trata de aquellas intervenciones que sitúan al equipo interventor como un acompañante o facilitador de los procesos de revinculación, donde lo fundamental es reconocer necesidades de distinta naturaleza (no solo psicosociales) e intentar resolverlas. Se trabaja desde la alianza, evitando estigmatizar o prejuiciar a las familias, asumiendo que las causas de la internación trascienden los comportamientos familiares y se relacionan, más bien, con dimensiones estructurales asociadas a vivienda, trabajo o salud.

En la siguiente cita, un diseñador explica cómo funcionó un programa piloto de desinternación, destacando la necesidad de producir intervenciones integrales donde se articulen respuestas intersectoriales que permitan sostener un trabajo en el largo plazo:

Por eso cuando la gente se va, la cuestión ya se desarma; pero en el fondo permitió visibilizar que muchas problemáticas de las familias no se iban a resolver por el acompañamiento terapéutico, sino que requería..., necesitaban de otro tipo de apoyo. Y que en la estructura tradicional de trabajo de las instituciones no están esos espacios de trabajo en red o de trabajo intersectorial, donde participen personas que tienen poder de toma de decisión para ir resolviendo ciertas cuestiones de las familias y de los niños. (Carlos, psicólogo, diseñador)

Las familias forman parte de los dispositivos de intervención y pueden participar - $\mathrm{O}$ no- de los procesos de reparación que experimentan los niños y niñas que viven en las residencias. En la siguiente cita, una ejecutora releva lo fundamental que resulta poner en valor a la familia en los procesos de intervención que se desarrollan en la residencia, reconociendo, en pequeños esfuerzos, el valor del vínculo como un recurso para el éxito de un proceso de intervención:

Entonces no le ponía el acento que nosotros le dábamos al valor de que el tío, que venía caminando desde Estación Central hasta la Casa Catalina para ahorrarse los ochocientos o setecientos pesos que costaba el pasaje, pero a cambio de eso traía una caja de helados para todos los niños de la residencia. ¿Cachái? [¿entiendes?]. Venía todos los jueves a visitar a su sobrina con todo el afán de poder recuperar su cuidado y su tuición lo antes posible 
¿sí? Y ya, tal vez él no tenía un mejor trabajo que el de antes, pero mira po’ [pues]..., el valor del vínculo. (Macarena, psicóloga, ejecutora)

Al mismo tiempo, es importante reconocer que muchas de las intervenciones de soporte surgen a partir de iniciativas que toman los mismos equipos, a partir de convicciones y recursos personales. La siguiente cita ilustra esto:

Cosas tan simples como trabajar con una familia migrante, por ejemplo, que no habla nuestro idioma, y la fundación no tenía un facilitador de idioma, el tribunal no tenía un facilitador de idioma. Y yo hablé con una amiga que conocía que trabaja en migración y que nos pudieron como conseguir un voluntario finalmente (...). Entonces, como cosas tan básicas como esas, que una persona pueda entender lo que tú le dices; eh... parte por esfuerzo de nosotros no más finalmente, de los profesionales. Yo creo que ahí es fundamental el compromiso que uno como profesional tenga más allá de la institución a la que uno representa. (Nora, trabajadora social, ejecutora)

\section{Intervenciones que visualizan a la familia como problema}

Se incluyen los discursos donde la familia es vista de forma amenazante, produciendo, consciente o inconscientemente, prácticas de alejamiento que impiden la preservación de los vínculos entre los NNA y sus contextos de origen. Esa distancia está, en ocasiones, fundada por el prejuicio hacia las familias, las cuales terminan enjuiciadas y cuestionadas en el rol protector, que ha fallado ante la vista de distintas instituciones. Para la propia residencia esta falla se transforma en una condición irreversible, que se representa como un daño del que hay que mantener a resguardo al niño o la niña.

Incluso lo otro, la lógica del despeje familiar que es cuando tú estás viendo la susceptibilidad de adopción o alguna relación de cuidado personal. El despeje familiar, básicamente, es la lógica de buscar a la familia. Esa es la lógica con la cual está concebida la legislación. Pero el mismo nombre de despeje familiar se ocupa en el otro sentido de sacar la familia; sacar, sacar, sacar y dejarlo solo al niño. O sea, básicamente, no es un despeje familiar de encontrar relaciones, sino que de romper relaciones. Y, básicamente, romper relaciones excluye automáticamente a los hermanos mayores. Los hermanos mayores están considerados en los protocolos del Sename, sino que buscan a los ascendentes, quizás un tío, pero los primos y los hermanos desaparecieron; y muchas veces son los hermanos mayores, o los primos o la gente más cercana los que pueden ser vínculos de apoyo. (Bastián, abogado, experto) 
Otra ejecutora avanza en su reflexión y propone que la distancia con las familias más bien esconde una dificultad de parte de los equipos respecto de lo complejo que resulta trabajar cuando, quien está al frente, encarna posiciones de exclusión que son muy difíciles de procesar. Entonces, ante esa dificultad, los equipos se cierran y terminan rivalizando con las familias o estigmatizándolas:

Pero sí hay algo como muy defensivo en los equipos, de no vincularse, de mantener como distancia. Porque también está eso otro, el prejuicio de que las familias son tal o tal cosa. Como está esto de que «la delincuencia», «los delincuentes» [gesto de comillas]. «Consumidores de drogas» [gesto de comillas]. Como que les da miedo la familia o las ven como inferiores también. Entonces eso entre miedo y, por el otro lado, lo que es esa distancia pa no vincularse con lo que remueve po' [pues]. (Vilma, psicóloga, ejecutora)

Porque también de repente había no sé po', familias con historias de vulneración de hijos mayores; pero las habilidades parentales, desde lo teórico, se observa que son, no son iguales para todos los hijos. $\mathrm{O}$ sea, tú puedes tener habilidades para el cuidado de un niño y no de otro. Eh, pero acá estaba igual ese estigma. «No, pero es que ya tuvo un hijo en residencia, entonces ¿cómo?, otra vez. ¿Será posible trabajar con ellos?». (...) Es bien castigador; me genera a mí como esa sensación de un sistema bien castigador con las familias de origen. (Nora, trabajadora social, ejecutora)

En la línea de lo propuesto anteriormente, las familias pierden legitimidad y terminan recibiendo intervenciones pedagógicas que no les reconocen recursos ni les permiten aportar, desde sus propios puntos de vista, al trabajo residencial. Se prescriben conductas que las familias deben incorporar como parte del tratamiento:

Los objetivos son súper comunes; son como estandarizados. Como que es difícil encontrar objetivos especializados. En una familia..., sí, sí. Y, ponte tú, desde lo psicológico es como bien reducido. Es bien informativo, bien instructivo desde el trabajo social también: tiene que hacer esto, tiene que ir para allá, tiene que esto. (Milena, psicóloga, ejecutora)

La estigmatización a las familias y su visualización como problema es una práctica muy presente en las residencias en particular, pero también forma parte de un nudo crítico de toda la intervención social que, desde sus orígenes, produjo una tutela moral sobre los pobres a partir de una suerte de etnocentrismo de clase, el cual establecía las conductas deseables a partir de un canon dominante (Castel, 2016). El estigma determina rutas de intervención que predispone a los equipos a leer la realidad de una cierta manera. El siguiente ejemplo ilustra muy bien este asunto: 
Y en uno de esos casos, me acuerdo que ingresó un niño cuya madre de verdad que llegaba a las ocho de la mañana y se iba a las ocho de la noche, quien estaba acusada de haber fracturado el cerebro de su hijo, después de que tuvo un hijo que falleció, pero que falleció a propósito de que estaba comiendo un koyac [dulce], se cayó y se ahogó. Pero a ella, por ese factor y no me acuerdo cuál más, se especulaba que tenía un síndrome de Münchausen, que es este síndrome en donde las madres enferman a sus hijos, ¿sí? Entonces (...), a ella la veo súper comprometida y en el otro sitio; digamos, acá puede haber una fragilidad y entonces, en paralelo, instamos a que hubiera mayores exámenes médicos de este niño para que apareciera lo que finalmente apareció y es que era casi que un niño cristal, que había tenido que ver efectivamente con un golpe, pero en un resbalín en una instancia de juego. (Macarena, psicóloga, ejecutora)

Uno de los aspectos que más preocupa es que, debido a la falta de un trabajo sistemático con las familias, la propia residencia - a veces sin mucha consciencia - termina alejando a las familias de los NNA residentes, confirmando el prejuicio que indica que las familias abandonan a sus hijos.

La mayoría de los lugares cuenta con horarios y días específicos, y muchos de esos horarios y días específicos no consideran las jornadas laborales de las familias y otras las figuras adultas (...). Por ende, muchas veces ellos no pueden ir en ese horario. Es así de sencillo; simplemente no pueden ir, porque si es de 2 a 3 de la tarde, un día miércoles y ellos están en plena jornada laboral, no existe ninguna posibilidad en el fondo de que ellos asistan. Y luego eso muchas veces es utilizado para decir que no existe interés suficiente en visitar a los niños, niñas y adolescentes que están en las residencias. Y eso es visualizado en el fondo como un abandono, como un desinterés, como una poca adherencia al trabajo con las familias, cuando en realidad ellos no tienen la posibilidad. (Susana, psicóloga, experta)

Otro elemento crítico es que el Estado establece trayectorias de intervención de largo plazo con las familias pobres, debido a la excesiva focalización de sus políticas y programas (Farías, 2019), que terminan sobreinterviniendo y, paradójicamente, volviendo crónicos algunos problemas que empeoran de manera significativa la situación que da origen a la intervención:

O sea, hay familias que han estado en Sename por diez años intervenidas. Y si tú lo veí [ves] del año cero, esto me lo contó una jueza. Si tu tení [tienes] una familia del año cero y tení a una persona, a un niño en Sename, y esa familia tiene otros tres niños fuera del Sename y ellos están en una terapia de rehabilitación de drogas, por ejemplo. Y el Estado interviene. Y años después están los cuatro niños en el Sename, dos están adoptados y los 
padres siguen drogadictos y tienen más hijos. Entonces la pregunta es: ¿qué hizo el Estado? Lo empeoró parece, ¿no? Entonces esas son dos tendencias, bastante perversas, que creo que Séname tiene. (Bastián, abogado, experto)

Como vemos, el trabajo con familias es heterogéneo ya que se evidencia la acción de diversos factores que inciden en su ejecución: valores, sesgos de clase, visiones de mundo, falta de recursos, institucionalidad débil, etc. Por su parte, los dos ejes que llamamos «prácticas de soporte» $\mathrm{y}$ «la familia como problema», al igual que en la categoría anterior, funcionan como extremos de un continuo, que permite caracterizar la coexistencia de prácticas disímiles y contradictorias al interior de las residencias.

\section{Discusión}

Esta investigación buscó comprender cómo se organizan las prácticas residenciales y qué arreglos (subjetivos y materiales) hacen los equipos cuando se ponen en contacto con los NNA y sus familias al interior de una residencia. Enfocarse en los equipos y sus posibilidades de acción nos permite complejizar las condiciones en las que realizan sus intervenciones y el mejoramiento de sus capacidades, que no pasa únicamente por la transferencia de contenidos vía capacitación, sino que se trata de algo mucho más profundo.

Las y los trabajadores que intervienen con la infancia vulnerada quedan inmersos en contradicciones sociales, las cuales enfrentan sin los recursos o condiciones suficientes para suplir las deficiencias de la política estatal que les ofrece un marco precarizado para su accionar (Sanfuentes \& Espinoza, 2017). En consecuencia, los agentes sociales deben redoblar esfuerzos para construir un espacio de trabajo abordable e inteligible; una especie de metanarrativa que entregue organización y coherencia a las prácticas, a los sucesos, a los sujetos y a las instituciones. De este esfuerzo emerge una lógica aprehensible para la intervención social, que la mayoría de las veces está inscrita en contextos cada vez más complejos y exigentes (Barna, 2014).

Lo que denominamos prácticas subjetivantes recoge ese esfuerzo cotidiano que los equipos desarrollan, desde abajo, de manera inorgánica, muchas veces por fuera de los lineamientos dispuestos desde las orientaciones para el acogimiento residencial, y que debiese funcionar como un sostén para los NNA y sus familias en su paso por la residencia. En algunos casos, se trata de prácticas que han sido acordadas y pensadas en espacios 
formalizados, como las reuniones de equipo, en otros. Se trata de apuestas personales que logran un efecto significativo para potenciar el bienestar de los NNA.

También podríamos entender las prácticas subjetivantes como formas de resistencia al interior del sistema residencial, permitiendo que la relación que sostienen adultos y NNA quiebre el encuadre tutelar aún imperante, generándose otros modos de relación que restituyan la agencia de los NNA y posibiliten su cuidado (García-Quiroga \& Urbina, 2021; Peña et al., 2014), poniendo como centro el establecimiento de un vínculo de confianza entre cuidadores y NNA. Esto implica una cierta distancia de las labores burocráticas instituidas, para hacer prevalecer el respeto y el reconocimiento del otro como bases del trabajo (Sánchez-Reyes et al., 2019).

Respecto al trabajo con familias, es posible constatar que existen distintos problemas en diferentes niveles. Por un lado, el estigma que portan las familias y el escaso trabajo que se desarrolla con estas (Defensoría de la Niñez de Chile, 2020; Contreras et al., 2015; Sename, 2018) sigue siendo un nudo crítico del modelo que requiere de cambios profundos. No solo ampliar la capacidad del equipo para cubrir también esa área, sino, por sobre todo, transformar las representaciones sobre la familia, reconfigurando un trabajo con muchas otras figuras más allá de la madre. Esta ha sido tradicionalmente convocada a estas intervenciones y responsabilizada por las dificultades que se producen en la crianza (Calquín et al., 2020; Calquín \& Guerra, 2018; Castillo et al., 2021).

Por otro lado, la dimensión familiar constituye un foco que viene a desplazar la desigualdad y la pobreza como causas de la internación y como contexto que explica la falla del sistema familiar en su labor de cuidado (Gillies, 2014). De este modo, todas las intervenciones dirigidas a las familias se limitan a modelar conductas sin modificar los contextos de vida, tales como el mejoramiento de habitabilidad o el acceso al trabajo. La pobreza y la desventaja social se transforman, de este modo, en fallas personales que es necesario corregir (Castillo et al., 2021; Edwards et al., 2015). La dificultad para mirar la dimensión estructural del problema de la niñez vulnerada se encuentra en los orígenes de la institucionalidad que surge en América Latina y demuestra que las políticas de niñez no han podido transformar los contextos que producen las causas de la internación de los NNA (Rojas-Novoa, 2021), perpetuando así los problemas que originan la internación a partir de la excesiva focalización (Farías, 2019).

El cuidado de la niñez institucionalizada y la promoción de sus vínculos requiere de un trabajo institucional que reconozca las historias y las trayectorias de los sujetos. Los estigmas y prejucios con los que opera el aparato residencial reproducen la violencia y 
exponen a los NNA a mayores niveles desprotección y desarraigo. Subjetivar las intervenciones es, en definitiva, construir la posibilidad de rehacer aquellos vínculos dañados por condiciones de injusticia y desigualdad, los cuales se han mantenido como telón de fondo desde los orígenes del sistema residencial en Chile (Delgado, 2001; Pinochet, 2017; Rojas, 2010).

Si bien existen múltiples sugerencias para superar la crisis del sistema residencial chileno, los últimos cambios implementados en las instituciones de administración directa, que solo impacta al $30 \%$ de la población total de NNA institucionalizados (nuevo modelo de residencias familiares) se centran, en mayor medida, en asuntos materiales como el mejoramiento de la infraestructura o la reducción del volumen de NNA atendidos (Defensoría de la Niñez de Chile, 2020). No obstante, lo que acá se propone se relaciona con la dimensión vincular, que muchas veces queda oculta tras los cambios materiales más visibles. De este modo, los resultados de esta investigación sugieren centrar la mirada en los equipos y comprender lo complejo que resulta llevar a cabo el trabajo cuando enfrentan escenarios de alta exigencia. Para lograr acompañar a las familias, en el marco de un proceso de reparación de los vínculos dañados por la violencia, es importante proveer un espacio de elaboración y reflexión colectiva, que permita comprender la complejidad de los cuidados, evitando intervenir a partir del estigma y los prejuicios. Contar con la posibilidad de intercambio y de aprendizaje a partir de la experiencia de los pares es un recurso escaso en las instituciones residenciales y puede ser considerado como una práctica subjetivante para las propias personas ejecutoras quienes, muchas veces, terminan siendo tratadas como un engranaje más dentro del circuito de las políticas públicas construidas desde el Estado subsidiario (Pavez-Mena, 2021). Reconocer y dar lugar a sus dificultades y ansiedades, desde la colaboración y la habilitación, más allá de lo que se visualiza en clave evaluativa (representado en el lenguaje de los indicadores y la estadística) es una necesidad urgente para mejorar los contextos de intervención (PavezMena, 2021, Sánchez \& Villarroel, 2017).

Esta investigación permitió conocer, desde distintos puntos de vista, lo que ocurre al interior del sistema residencial poniendo foco en los actores y sus prácticas. Sin embargo, está lejos de captar el fenómeno en su total magnitud, debido a la heterogeneidad de las instituciones que componen el campo de lo residencial. Se trata de una mirada profunda, pero parcial y acotada, que comienza a ganar terreno progresivamente dentro del campo de investigación cualitativa (García-Quiroga \& Salvo, 2020; García-Quiroga \& Urbina, 2021; Hueche et al., 2019), que se propone hacer un acercamiento intensivo a 
aquello que queda eclipsado tras los hechos de violencia ampliamente reportados en los últimos años (ONU, 2018; PDI, 2018; Sename, 2018; UDP, 2017).

\section{Referencias}

Baratta, A. (2008). Democracia y derechos del niño. Unicef.

Barna, A. (2014). Clasificaciones y estimaciones en la gestión de la infancia con derechos vulnerados: prácticas cotidianas de intervención en un dispositivo estatal del conurbano bonaerense. Revista Antropolítica, 36(1), 113-148.

Batthyàny, K., Genta, N., \& Perrota, V. (2013). El discurso experto sobre el cuidado desde una perspectiva de género: análisis comparativo entre el cuidado infantil y de adultos/as mayores en Uruguay. Revista Austral de Ciencias Sociales, (25), 23-46. https://doi.org/10.4206/rev.austral.cienc.soc.2013.n25-02

Bührmann, A. D., \& Schneider, W. J. (2019). Análisis de dispositivos: reflexiones sobre la relación entre discursos, sujetos, objetos y prácticas. En B. Herzog, \& J. Ruiz-Ruiz (Eds.), Análisis sociológico de discurso: enfoques, métodos y procedimientos (pp. 251-278). Universitat de Valencia.

Bustelo, E. (2007). El recreo de la infancia: argumentos para otro comienzo. Siglo Veintiuno. Calquín, C., \& Guerra, R. (2018). Gobernando la infancia pobre: familiarización y neuropsicologización en el programa Chile Crece Contigo. En J. Arce-Riffo (Ed.), El Estado y las mujeres: el complejo camino hacia una necesaria transformación de las instituciones (pp. 135-153). RIL Editores.

Calquín, C., Guerra, R., Vásquez-Vásquez, S., \& Yáñez-Urbina, C. (2020). Construyendo hechos: análisis de las metáforas utilizadas en la producción científica chilena sobre apego e infancia temprana. Límite. Revista Interdisciplinaria de Filosofía y Psicología, 15, 1-20. https://doi.org/10.4067/So718-50652020000100218

Cantwell, N., Davidson, J., Elsley, S., Milligan, I., \& Quinn, N. (2012) Avanzando en la implementación de las «Directrices sobre las modalidades alternativas de cuidado de los Niños».

Centre for Excellence for Looked After Children in Scotland. https://bit.ly/3svvEsA Cárdenas, S. (2013). Mudanzas de la infancia: entre la institucionalización, la ciudadanización y la mercantilización. Clacso.

Castel, R. (2016). La metamorfosis de la cuestión social: una crónica del salariado. Paidós.

Castillo, P. (2015). Los saberes psicológicos en el neoliberalismo: el caso de las políticas sociales y la teoría del apego en Chile. Universitas Psychologica, 14(4), 1325-1338. https://doi.org/10.11144/Javeriana.up14-4.spnc 
Castillo, P., González, A., \& Cortes, R. (2021). Representaciones de infancia en el Chile dictatorial (1973-1980): articulaciones con la política neoliberal y la mercantilización de las instituciones de cuidado. Espacio, Tiempo y Educación, 8(1), 147-169.

Comisión Interamericana de Derechos Humanos. (2013). Derecho del niño y la niña a la familia: cuidado alternativo. Poniendo fin a la institucionalización en las Américas. https:// www.oas.org/es/cidh/infancia/docs/pdf/Informe-derecho-nino-a-familia.pdf

Consejo Nacional de la Infancia. (2017). Orientaciones para la intervención familiar con niños y niñas institucionalizados. Modelo de intervención para la revinculación familiar de niños y niñas de o a 3 años que permanecen en residencias de protección. https:// biblioteca.digital.gob.cl/handle/123456789/1132

Contreras, J. I., Rojas, V., \& Contreras, L. (2014). Análisis de programas relacionados con la intervención de niños, niñas y adolescentes vulnerados en sus derechos: la realidad chilena. Psicoperspectivas, 14(1), 89-102. https://doi.org/gjsj85

Contreras, L., Crettier, B., Ramm, A., Gómez, E., \& Burr, F. (2015). Informe final: estudio de caracterización del vínculo familia-niñas, niños y adolescentes y de las intervenciones de fortalecimiento familiar. Instituto de Investigación en Ciencias Sociales; Fundación San Carlos de Maipo; Sename.

Defensoría de la Niñez de Chile. (2020). Informe anual 2020. https://bit.ly/3LpnISk

Delgado, M. (2001). La infancia abandonada en Chile. 1770-1930. Revista de Historia Social $y$ de las Mentalidades, 5(1), 101-126.

Donzelot, J. (1998). La policía de las familias. Pre-Textos.

Edwards, R., Gillies, V., \& Horsley, N. (2015). Brain science and early years policy: Hopeful ethos or «cruel optimism»? Critical Social Policy, 35(2), 167-187. https://doi.org/hgdv

Eliacheff, C. (2002). Del niño rey al niño víctima: violencia familiar e institucional. Nueva Visión.

Farías, A. (2003). El difícil camino hacia la construcción del niño como sujeto de derechos. Revista de Derechos del Niño, (2), 187-224.

Farías, A. (2019). Políticas sociales en Chile: trayectorias de inequidades y desigualdades en distribución de bienes y servicios. Ediciones UAH.

Forni, P. (2010). Los estudios de caso: orígenes, cuestiones de diseño y sus aportes a la teoría social. Miríada, 3(5), 61-80.

Foucault, M. (1978). La verdad y las formas jurídicas. Gedisa.

Gainza, A. (2006). La entrevista en profundidad individual. En M. Canales-Cerón (Coord.), Metodologías de investigación social: introducción a los oficios (pp. 219-264). LOM Ediciones. 
García-Méndez, E. (1994). Derecho de la infancia-adolescencia en América Latina: de la situación irregular a la protección integral. Forum Pacis.

García-Quiroga, M., \& Hamilton-Giachritsis, C. (2014) In the name of the children: Public policies for children in out-of-home care in Chile. Historical review, present situation and future challenges. Children and Youth Services Review, 44, 422-430. https:// doi.org/10.1016/j.childyouth.2014.07.009

García-Quiroga, M., \& Salvo, I. (2020). Too vulnerable to participate? Challenges for meaningful participation in research with children in alternative care and adoption. International Journal of Qualitative Methods, 19, 45-56. https://doi.org/gp87

García-Quiroga, M., \& Urbina, C. (2021). «Ella es mi favorita»: perspectivas infantiles sobre el buen cuidado en residencias. Revista Latinoamericana de Ciencias Sociales, Niñez y Juventud, 19(3), 1-24. https://doi.org/10.1160o/rlcsnj.19.3.4179

Gillies, V. (2014). Troubling families: Parenting and the politics of early intervention. En S. Wagg, \& J. Pilcher (Eds.), Thatcher's grandchildren, politics and childhood in the twentyfirst century (pp. 204-224). Palgrave Macmillan. https://doi.org/hgdz

Gobierno de Chile. (2018). Acuerdo Nacional por la Infancia. https://bit.ly/3rD48tR

Goffman, E. (2007). Internados: ensayos sobre la situación social de los enfermos mentales. Amorrortu.

Grinberg, J. (2016). Los Suárez y las instituciones del sistema de protección de la infancia: un análisis sobre las formas contemporáneas de gobierno de las familias en contextos de desigualdad y pobreza. Revista Latinoamericana de Ciencias Sociales, Niñez y Juventud, 14(1), 631-643.

Hernández, R., Fernández, C., \& Baptista, P. (2010). Metodología de la investigación. McGraw-Hill.

Hogar de Cristo. (2017). Del dicho al derecho: estándares de calidad para residencias de protección de niños y adolescentes. Dirección Social Nacional.

Hueche, C., Lagos, G., Ríos, N., Silva, E., \& Alarcón-Espinoza, M. (2019). Vínculos afectivos en adolescentes institucionalizados, Chile. Revista Latinoamericana de Ciencias Sociales, Niñez y Juventud, 17(2), 1-19 https://doi.org/10.1160o/1692715x.17217

Instituto Nacional de Derechos Humanos. (2017). Misión de observación Sename 2017. https://bibliotecadigital.indh.cl/handle/123456789/1148

Isacovich, P., \& Grinberg, J. (2020). Introducción: los derechos de las infancias y las juventudes: debates e interrogantes a la luz del zo aniversario de la Convención de los Derechos del Niño. En P. Isacovich, \& J. Grinberg (Comps.), Infancias y juventudes a 30 años de la Convención sobre los derechos del Niño. Edunpaz. https://bit.ly/3JhMVMI 
Lecannelier, F. (2006). Efectos de la separación temprana: una mirada desde los procesos de institucionalización. Fundación San José.

Marchant, M. (2007). Reflexiones en torno a los procesos de institucionalización y separación afectiva temprana en el contexto de un hogar de protección de lactantes. Revista de Psicología, 16(1), 123-145. https://doi.org/10.5354/0719-0581.2007.18441

Marchant, M. (2014). Vínculo y memoria: acompañamiento terapéutico con niños internados. Cuarto Propio.

Mide UC. (2013). Informe final: un diagnóstico del Sistema de Cuidados Alternativos del Estado de Chile. Niños, niñas y adolescentes privados de cuidado parental o en riesgo de estarlo. Universidad Católica de Chile. https://bit.ly/3JebbPF

Milanich, N. (2001). Los hijos de la Providencia: el abandono como circulación en el Chile decimonónico. Revista de Historia Social y de las Mentalidades, 5(1), 79-100.

Minnicelli, M. (2004). Infancias públicas: no hay derechos. Novedades Educativas.

Morales-Retamal, C. (2014). La subjetividad internada, análisis crítico del sistema de protección residencial en Chile. De Familias y Terapias, (23), 1-27.

Morales-Retamal, C. (2019). Separación y revinculación familiar: el lugar de los vínculos en residencias de protección. Revista Sul-Americana de Psicologia, 7(2), 46-65. https:// doi.org/10.29344/2318650X.2.2152

Morales-Retamal, C., Morales, M., \& Olivares-Espinoza, B. (2015). La institucionalización de la niñez: la experiencia de acompañamiento terapéutico con niños, niñas y sus familias. De Familias y Terapias, (39), 51-68.

Muñoz-Guzmán, C., Fischer, C., Chia, E., \& LaBrenz, C. (2015). Child welfare in Chile: Learning from international experiences to improve family interventions. Social Sciences, 4(1), 219-238. https://doi.org/10.3390/socsci4010219

Organización de las Naciones Unidas. (2009). Directrices sobre las modalidades alternativas de cuidado de los niños. https://www.acnur.org/fileadmin/Documentos/BDL/ 2010/8064.pdf?file=fileadmin/Documentos/BDL/2010/8064

Organización de las Naciones Unidas. (2018). Informe de la investigación relacionada en Chile en virtud del artículo 13 del Protocolo Facultativo de la Convención de los Derechos del Niño relativos a un procedimiento de comunicaciones.

Pavez-Mena, J. (2021). Tensiones y adecuaciones de los trabajadores en el marco de la ejecución de la política social chilena. Quaderns de Psicologia, 23(2), 1-21. https:// doi.org/10.5565/rev/qpsicologia.1610 
Peña, M., Chávez, P., \& Vergara, A. (2014). Los niños como agentes políticos: tácticas cotidianas de resistencia en niñas chilenas de estrato socioeconómico medio. Sociedad e Cultura, $17(2)$, 291-30o. https://doi.org/10.5216/sec.v17i2.29135

Pilotti, F. (2001). Globalización y Convención sobre los Derechos del Niño: el contexto del texto. Naciones Unidas. https://bit.ly/3B8bopE

Pinochet, N. (2017). El Sename: crónica de una crisis: una mirada psicoanalítica sobre el sujeto de derecho y la institución de protección de la infancia. Castalia, 28(4), 54-68. https://doi.org/10.25074/07198051.4.596

Policía de Investigaciones de Chile. (2018). Informe: análisis del funcionamiento residencial en centros dependientes del Servicio Nacional de Menores. https://bit.ly/3smREWs

Rojas, C. (2020). Abandonados: vida y muerte al interior del Sename. Penguin Random House. Rojas, J. (2010). Historia de la infancia en el Chile Republicano 1810-2010. Junta Nacional de Jardines Infantiles.

Rojas-Novoa, M. (2021). Protección de la infancia y saberes expertos: un archivo interamericano como campo etnográfico. Revista Latinoamericana de Ciencias Sociales, Niñez y Juventud, 19(2), 1-24. https://doi.org/10.1160o/rlcsnj.19.2.4574

Sánchez, M., \& Villarroel, R. (2017). Tensiones en la intervención social: (des)encuentros en la relación Estado-ONG. Estudio de caso sobre ONG que opera la política social de infancia. Revista de Trabajo Social, (91), 3-16. https://doi.org/10.7764/rts.91.1-16

Sánchez-Reyes, J., Cantor-Jiménez, J., Castro-Sardi, X., \& Bolaños, Y. (2019). Concepciones de niño y modos de relación de cuidadores y profesionales con niños institucionalizados, Colombia. Revista Latinoamericana de Ciencias Sociales, Niñez y Juventud, $17(2)$, 1-24. https://doi.org/10.11600/1692715x.17209

Sanfuentes, M., \& Espinoza, T. (2017). Crisis del Sename en Chile: una mirada desde adentro. Centro de Estudios de Conflicto y Cohesión Social.

Servicio Nacional de Menores de Chile. (2018). Anuario estadístico 2017. https://bit.ly/ 3 fcoag Z

Silva, D., \& Domínguez, P. (2017). Desinternar, sí. Pero ¿cómo?: controversias para comprender y transformar las propuestas institucionales de protección a la infancia y la adolescencia. La Barca; Unicef. https://www.bibliotecaunicef.uy/doc_num.php?explnum_id=161

Stein, C., \& Mankowski, E. (2004). Asking, witnessing, interpreting, knowing: Conducting qualitative research in Community Psychology. American Journal of Community Psycho-

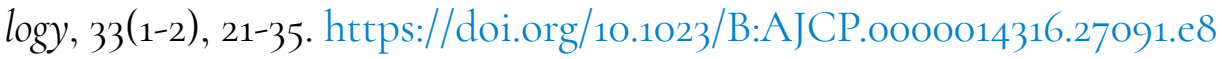

Unicef. (2002). Internación de niños: ¿el comienzo del fin? https://www.unicef.cl/ archivos_documento/2/internacion.pdf 
Universidad Diego Portales. (2008). Informe anual sobre Derechos Humanos: derechos de niños, niñas y adolescentes. Ediciones UDP.

Universidad Diego Portales. (2017). Informe anual sobre Derechos Humanos. Sename: el rol del Estado, la tutela judicial de niños, niñas y adolescentes y la relevancia penal de la crisis. Ediciones UDP.

Villalta, C. (2013). Un campo de investigación: las técnicas de gestión y los dispositivos jurídico-burocráticos destinados a la infancia pobre en la Argentina. Civitas. Revista de Ciências Sociais, 13(2), 245-268. https://doi.org/10.15448/1984-7289.2013.2.15482

Villalta, C. (2021). Antropología de las intervenciones estatales sobre la infancia, la adolescencia y la familia: etnografiando prácticas cotidianas, construyendo perspectivas analíticas. Cuadernos de Antropología Social, (53), 21-37. https://doi.org/hgdg

Wieviorka, M. (2003). La violencia: destrucción y constitución del sujeto. Espacio Abierto, $10(3), 337-347$. 